\title{
Experiencing information, acquiring knowledge, and making decisions regarding web accessibility
}

\author{
Yonit Rusho, University of Haifa, Israel, yonit.rusho.17@gmail.com \\ Daphne R. Raban, University of Haifa, Israel, draban@univ.haifa.ac.il
}

\begin{abstract}
We address the disparity between availability of information and its actual implementation in decisions in the context of Web Accessibility $(W-A)$. Organizations are aware of the importance of $W$-A for alleviating barriers to interaction with online platforms, such as visual, motor, hearing, and cognitive impairments. Information regarding inclusion design is abundant but implementation is partial. Applying $W$-A refers to implementing technical and graphical solutions to assist people with disabilities in access and use of online systems. We hypothesized that people who produce information are more likely to decide to apply $W$ - $A$ than information consumers. $A$ total of 651 participants took part in a set of eight experiments. Consumers read information about $W-A$ and producers created the same information. Decisions regarding applying $W$ - $A$ knowledge were measured before and after information use. Results reveal that (1) collaborative information consumption is related to a change in decision; (2) The extent of change in decision relates to the number of collaborating producers; (3) Collaborative information production increases the intent to make a practical decision to apply $W$-A. This study emphasizes the interaction between information experience and peer collaboration regarding applying $W$ - $A$ knowledge. Insights contribute to organizations knowledge definitions while highlighting the impact of group activity on decision-making.
\end{abstract}

Keywords: Information experience, Web Accessibility, online collaborative platforms.

\section{Introduction}

Accessibility has become an important goal in the drive to promote inclusion in today's information society (Freire et al., 2008). New tools and techniques have evolved to enable everyone everywhere to access websites and online information systems (Freire et al., 2007; Ramakrishnan et al., 2017). Nevertheless, while research shows that attitudes toward accessible content are positive and encouraging (Yesilada et al., 2015), some studies reveal that Web Accessibility (W-A) is partially implemented and supported (Alahmadi \& Drew, 2017; Rau et al., 2016).

As awareness of inclusive design rises, and information regarding $\mathrm{W}-\mathrm{A}$ is available and abundant, professionals such as teachers, publishers, universities, website developers, marketing people etc., can make a decision to use this information for the purpose of increasing inclusiveness and accessibility in online systems for people with disabilities (Freire et al., 2008). Researchers define frameworks for the design of accessible collaborative tools for educators (Flórez-Aristizábal et al., 2019) or considerations for accessibility improvements for graphical designers (Li et al., 2019). If 
knowledge management refers to getting the right knowledge to the right people and helping people to share and improve organizational performance (Girard \& Girard, 2015), then W-A support can improve knowledge management due to inclusion design benefits. However, people and organizations are not eager to change the status quo, and prefer to be entrenched in their original views (Lord et al., 1979). This is one reason why inclusive design is still an unfulfilled goal.

The current research aims to determine how two types of information experience affect decision making to apply inclusive design, specifically human W-A for the needs of people with disabilities. Information experiences include consumption or production of information. Hence, this study places participants in the position of consuming or producing information (a presentation about $\mathrm{W}-\mathrm{A}$ ) in order to measure influence on decision-making. Both information consumers and producers make use of information. They may then use the knowledge gained to make a decision whether to invest in supporting accessibility for people with disabilities or not. Support is reflected in technical and graphic actions as well as content changes on online websites. The decision is made after using the information and in fact understanding the need, benefits and manner in which websites can be supported. The working hypothesis is that people who produce information are more likely to make practical decisions than people who consume information. In addition, this research examines peer effects on decision making regarding $\mathrm{W}-\mathrm{A}$. The working hypothesis is that when decisions are made in the presence of peers, intent to make a practical decision to apply WA increases. Conclusions can be applied in organizations' knowledge management practices.

This paper opens by describing the importance of applying inclusion, specifically W-A. Since we are interested in turning available information into actionable knowledge, this paper continues with highlighting the role of information in making an actionable decision to implement W-A knowledge. In the context of information, we explain the experiential nature of information goods, used individually or in groups, as both modes are relevant to organizational activities. The study's hypotheses follow the theoretical background. The methods section describes a knowledge test administered before the experimental assignment. Experiments were conducted with eight experimental groups. Finally, the paper presents and discusses the resulting effects of the dependent variable: decision to implement W-A.

\section{Theory}

\section{Willingness to Support Web Accessibility}

The structure of the web supports browsing with any hardware, device, language, and location, and by people who have any physical and mental ability (Henry et al., 2014). Tim Berners-Lee, Director of the World Wide Web Consortium (W3C) and inventor of the World Wide Web, said in 1997: "The power of the web is in its universality. Access by everyone regardless of disability is an essential aspect" (Berners-Lee, 2013, p. 2). Yet today, over 20 years since this important statement was made, the universal web does not realize its full potential.

Although W-A relates to people with disabilities such as visual, motor, hearing, and cognitive impairments, improvements in accessibility benefit everyone (Henry et al., 2014). One benefit of 
$\mathrm{W}-\mathrm{A}$ is considerably higher content quality. There is a significant relationship between the level of accessibility and the quality of the web contents (Lorca et al., 2018).

The web offers free and abundant information explaining how to apply W-A. Examples of online information that assists in supporting W-A include open source repositories of W-A implementation, code examples and published Web Content Accessibility Guidelines for web developers, designers and content authors. In addition, accessibility tools have been developed to aid designers, editors and developers. For example, Wave ("WAVE Web Accessibility Tool") and W3C validation service ("The W3C Markup Validation Service").

However, there are factors which delay full W-A, such as lack of management interest, insufficient accessibility education, and low awareness (Hong et al., 2015). This implies that availability of information about $\mathrm{W}$-A provides partial motivation to introduce web site accessibility. We are interested in turning the available information into actionable knowledge.

Various forms of information support the purpose of increasing awareness to the additional benefits of $\mathrm{W}-\mathrm{A}$, beyond those for people with disabilities. For example, overlap between designing for accessibility and designing solutions for mobile phones is likely to increase understanding by developers who can more efficiently meet both goals (Henry \& Thorp, 2012). Awareness in China shows that e-government websites had improved significantly with respect to accessibility due to the promulgation of accessibility regulations. Lack of awareness rather than lack of technical skills is the reason for low W-A in China (Rau et al., 2016). Brown and Hollier (2015), in their study of universities, supported these findings, and claim that disability awareness, more than technology and policy, is the primary obstacle to a more universally accessible web. Eventually, notwithstanding that information is free and public, if awareness is low, searching for and using this information is also limited in organizations and by individuals. The following section explains how varying the usages of information may help to increase awareness to apply knowledge regarding $\mathrm{W}-\mathrm{A}$.

\section{Information Consumption and Production as Web Experiences}

Information is an experience good, meaning that the actual evaluation of the product is revealed to the user only after it is used (Alstyne, 1999; Nelson, 1970). Information experiences on the web vary. For this research, we define two types of information experience in online environments: consumption and production. Consumption describes users who search, select, collect and read, view or listen to information published by others. In the current research, the information consumption experience is accomplished by exposure to information, by reading and responding to it within a specially designed experimental system described in the Method section.

The second type of online information experience is production of information, which occurs when participating in a creation process of information good such as writing text, preparing a presentation, filming a video clip and so on. In the present research, information production experience follows a circular five-stage process in which an information product, a presentation, is created (Rusho \& Raban, 2019). In previous research, we showed that when individuals are engaged in producing information they develop a higher evaluation of their self-created information product as compared to an identical information product created for them (Rusho \& Raban, 2018, 2019). This is a form of expression of the Ikea Effect as applied to digital information 
(Norton et al., 2012). Based on our earlier findings we assume that the enhanced perceived value of self-produced information will lead to more positive and actionable decisions compared with the traditional consumption of information, such as exposure to and reading of information.

The next section describes changes expected in information experiences as a result of peer presence, which is an integral behavior of ongoing activities online and in organizational contexts.

\section{Information Web Experiences in Collaborative Environments}

In this research, web experience refers to consumption or production of information, specifically, a professional presentation about W-A. Yet, the evolution of computing and communication technologies changes the way people can meet and make group decisions (Kiesler \& Sproull, 1992). Web communication tools, such as blogs, social networking sites, and wikis, allow users to share content with each other and collaborate online (Soltysik-Piorunkiewicz, 2015). Indeed, consumption and production occurring online often take place in the presence of others. In addition, collaborative activities, such as sharing goods and services on the web, impact every sector of society (Owyang et al., 2013). With the growth and implementation of social and online collaborative platforms in everyday life, this research addresses web experience in both individual and social contexts and the effect of these varying experiences on W-A support decisions.

The first type of collaborative web experience relates to collaborative consumption. In the current research we define collaborative consumption as the activity of granting of access at a certain point of time, by multiple obtainers, to a shared version of an information good. Massive Open Online Courses (MOOCs) are an example of collaborative consumption, where collaborative access to resources increases motivation and commitment (Borras-Gene et al., 2016).

The second type of collaborative web experience relates to collaborative production. Collaborative platforms reduce time and effort required for the production of information and increase the quality of the generated information (Kavasidis et al., 2014). Wikipedia and Stack Overflow are examples of collaborative products. Wikipedia is a unique knowledge resource created by active peers around the world (Chen et al., 2017). In the software development and crowdsourcing knowledge fields, Stack Overflow is a question-answering distributed repository of knowledge created in a collaborative process (Anderson et al., 2012). Collaborative information production activities create business value for consumers and organizations. For example, users may collaborate in the process of offering design ideas to a particular jewelry company (Wilson et al., 2017). Similarly, in the current research, peer production refers to multiple producers contributing to the creation of a single copy of an information product: multiple teachers producing a joint presentation.

In both collaborative web experiences, people arrive to the task with prior knowledge and proficiencies. Their prior experiences contribute to the collaborative task (Sillito Walker \& Bonner, 2018). In addition to prior knowledge, collaborative technologies such as wikis increase the quality of peers' decisions for intellectual tasks. Quality decision is defined according to participants' feeling toward team output during the decision making process (Heidrich et al., 2015). Other collaborative platforms might be Stack Overflow and shared Google Docs for collaborative online documents editing. 


\section{Research Questions and Hypotheses}

Having explained that W-A information is widely available but underutilized, this study examines whether consumption or production of information, by individuals or collaboratively, relate to practical decisions to apply W-A. In order to fine-tune the decisions to apply W-A, we examine three levels of decision making: (a) change in decision; (b) the extent of change; and (c) the willingness to make a practical decision to apply $\mathrm{W}-\mathrm{A}$. The three levels are represented in three sequential research questions, as seen in Figure 1.

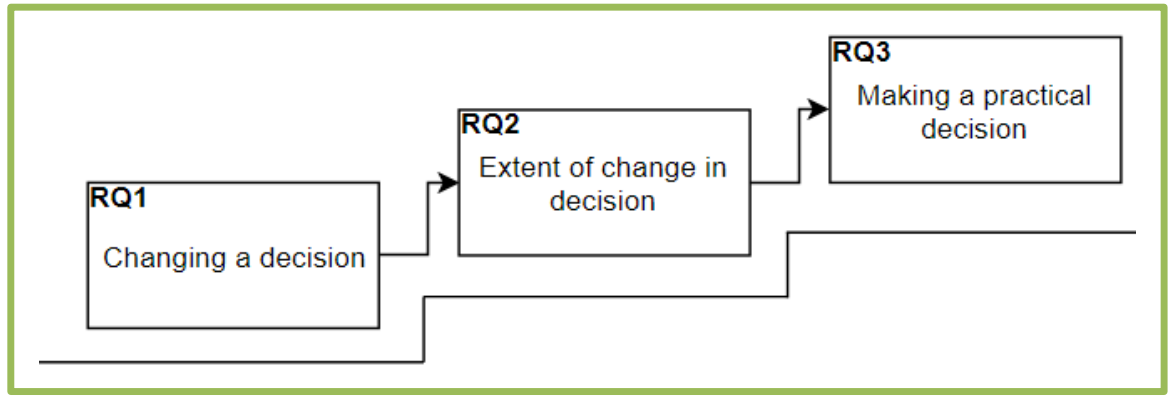

Figure 1. Levels of information influence on decision regarding W-A

Each research question is related to a level of decision making, as shown in Figure 1. The corresponding research questions are:

RQ1. Do information experiences induce a change in decision?

RQ2. Do information experiences affect the extent of change in decisions?

RQ3. Do information experiences induce more practical decisions?

All hypotheses are examined in four independent groups: (1) individual consumers of information; (2) individual producers of information; (3) consumption as part of a collaborative experience in three levels; and (4) production as part of a collaborative experience in three levels.

Having explained the roles of information usage in the process of decision-making, the experiential nature of information, and the differences between consuming and producing information as individuals or as part of a collaboration experience, the first hypothesis is:

H1: Consuming or producing information in an online collaborative environment causes a change of decision to adopt W-A.

Individual information production enhances information value perception more than information consumption (Rusho \& Raban, 2019). We assume that collaborative experiences will show a similar effect on decision making, i.e. collaborative production enhances extent of change in decision to apply W-A. Therefore, the second hypothesis is:

H2: A collaborative information production experience increases the extent of change in decision to apply W-A more than a collaborative consumption experience.

While RQ1 and RQ2 investigate whether a change of decision will occur and to what extent, RQ3 investigates the link between information usage experience and willingness to make a practical 
decision to support W-A. To answer RQ3, two approaches are employed. The first compares participants who used information to participants who did not use information. The second refers only to participants who experienced information as well as compares consumption and production of information in various peer group sizes in an online collaborative platform.

The first approach in answering RQ3 examines whether using information affects willingness to make a practical decision to apply W-A. Without the use of information, it is not relevant to calculate a change in decision. Therefore, the third hypothesis refers to a final decision made as a result of using information compared to an initial decision made without the use of the information:

\section{H3: Information experience promotes a practical decision to apply Web Accessibility.}

The second approach in answering RQ3, examines the experience of information by comparing consumption and production usages of information. The final hypothesis is, therefore, as follows:

H4: A collaborative information production experience increases the probability of making a practical decision compared to a collaborative consumption experience.

In summary, Figure 2 shows the hypotheses in the context of the research model.

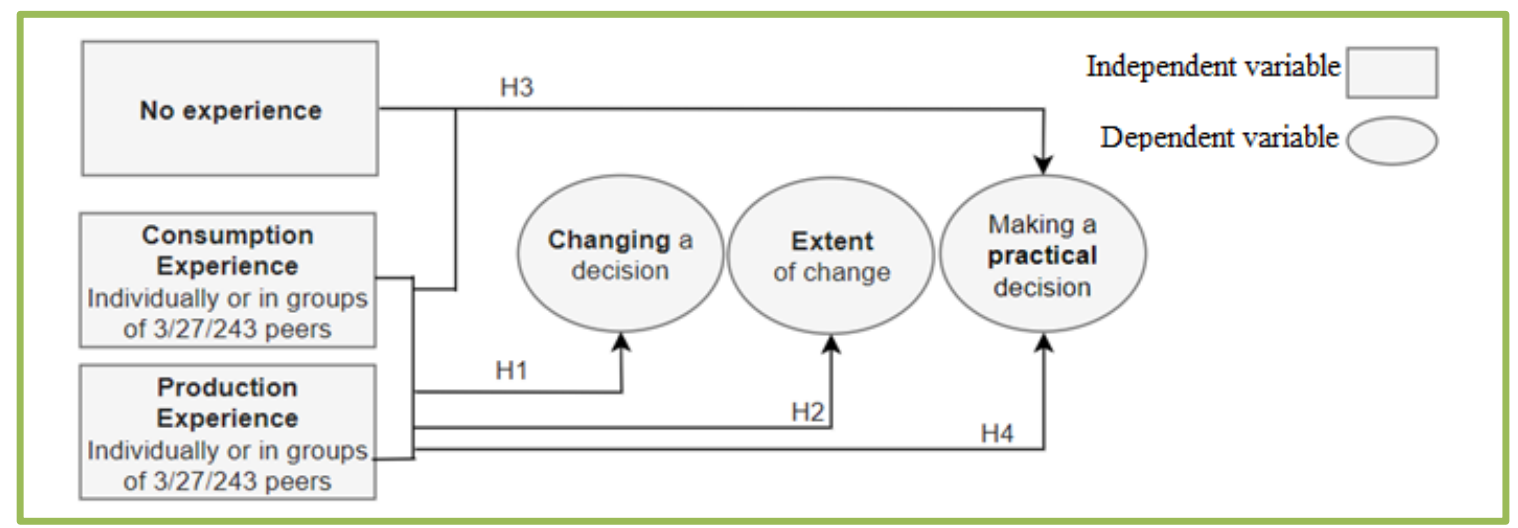

Figure 2. Research model

\section{Method}

With the purpose of examining the influence of information experience on decision to apply W-A knowledge, the main method was a series of digital experiments.

Study participants: A total of 651 participants took part in eight experimental treatments. All were adults with an academic education. Each participant received a small remuneration for participation, about \$2 per person. Partial support for this research was provided by the I-CORE Program of the Planning and Budgeting Committee and the Israel Science Foundation. The experiments were performed online.

Study participants' prior knowledge in the field of W-A: The purpose of the knowledge quiz was to verify the normal distribution of participants' knowledge in the field of W-A. The Knowledge Quiz included seven questions regarding W-A. Results of the quiz are displayed in Table 1. 
Table 1. W-A Knowledge Quiz Results

\begin{tabular}{|c|c|}
\hline Number of Participants & Number of correct answers \\
\hline 89 & 0 \\
\hline 187 & 1 \\
\hline 187 & 2 \\
\hline 116 & 3 \\
\hline 47 & 4 \\
\hline
\end{tabular}

Procedure

At the heart of the experiment lies an information-based task, in which participates consume or produce a professional presentation regarding $\mathrm{W}-\mathrm{A}$. The presentation included information about the support of visual, motor, hearing, and cognitive impairments. Each participant was randomly assigned to one of eight groups. In the four consumption groups, consumers were presented with the scenario that they are students in an online international course about web technologies, including the topic of W-A. As part of the scenario, the university introduced them to an online collaborative platform for viewing presentations with additional information relevant to the course. Consumers were offered the option to acquire a presentation concerning W-A while being informed about the number of peers who simultaneously gained access to the presentation in the online collaborative platform. The act of acquisition by submitting a purchasing bid was designed to enhance their role as consumers. In the four production groups, producers read a description that they are lecturers in an online international course and, thus, they are expected to create the same information (presentation) described above, via an online collaborative platform. Producers were offered to sell their creation to a publishing company in order to enhance their self-perception as producers. To summarize, in a set of eight experiment groups, participants were randomly assigned to one of groups 1-8, as shown in Table 2 .

Table 2. Response Counts of The Variables

\begin{tabular}{|c|c|c|c|}
\hline & Experience Type & Number of Peers & Numbers of Participants \\
\hline 1 & \multirow{4}{*}{ Consumption } & 1 & 96 \\
\hline 2 & & 3 & 81 \\
\hline 3 & & 27 & 85 \\
\hline 4 & & 243 & 68 \\
\hline 5 & \multirow{4}{*}{ Production } & 1 & 100 \\
\hline 6 & & 3 & 76 \\
\hline 7 & & 27 & 70 \\
\hline 8 & & 243 & 75 \\
\hline
\end{tabular}


Participants progressed throughout the experiment across four steps. In the first step participants indicated their decision to apply W-A knowledge both before and after using information. In the second step participants submitting a bid to purchase or sell information: Beside the aforementioned aim to create a realistic consumption or production experience, price bids were instrumental in identifying participants who made their decisions without exposure to information consumption or production. Those participants are a control group for hypotheses $\mathrm{H} 3$ and H4. A total of 576 participants managed to purchase or sell information, the other 74 participants made decisions without exposure to information. Aiming in making the experiment as similar to reality as possible, participants were informed about the existing of a (random) market price. Participants did not know the market value and were unable to affect it. Participants had three attempts to buy or sell the information (presentation). In the third step participants consumed or produced the information. The information consumption process includes reading and interacting with a presentation. The information production process included five steps of the conceptual model: specification, design, implementation, validation and evolution (Rusho \& Raban, 2019). Accordingly, producers were asked to select audience, purpose, and content for the presentation. In the fourth step participants indicated again their decision to apply W-A.

Experience Interface: Figure 3 shows a sample screenshot of the experiment. Next to the eye icon appears an indication to the producer that additional 243 peers are collaborating. A list of 243 names and photos is displayed on the left side. To clarify, the screenshot shows one of the decisions presented to the producers regarding W-A. The progress bar on the bottom gives the participants an indication regarding how many peers have joined. In addition, during the process, producers received feedback regarding their choices. If their choice conformed to the majority opinion, they were presented with a green V icon and text in the following style: "14 out of 243 answered like you" (as can be seen in Figure 3, for Group 8 of Table 2). If their choice was different from majority opinion, they were presented with a red sign. The user instructions stated: "The presentation will reflect the majority vote on the choice of content."

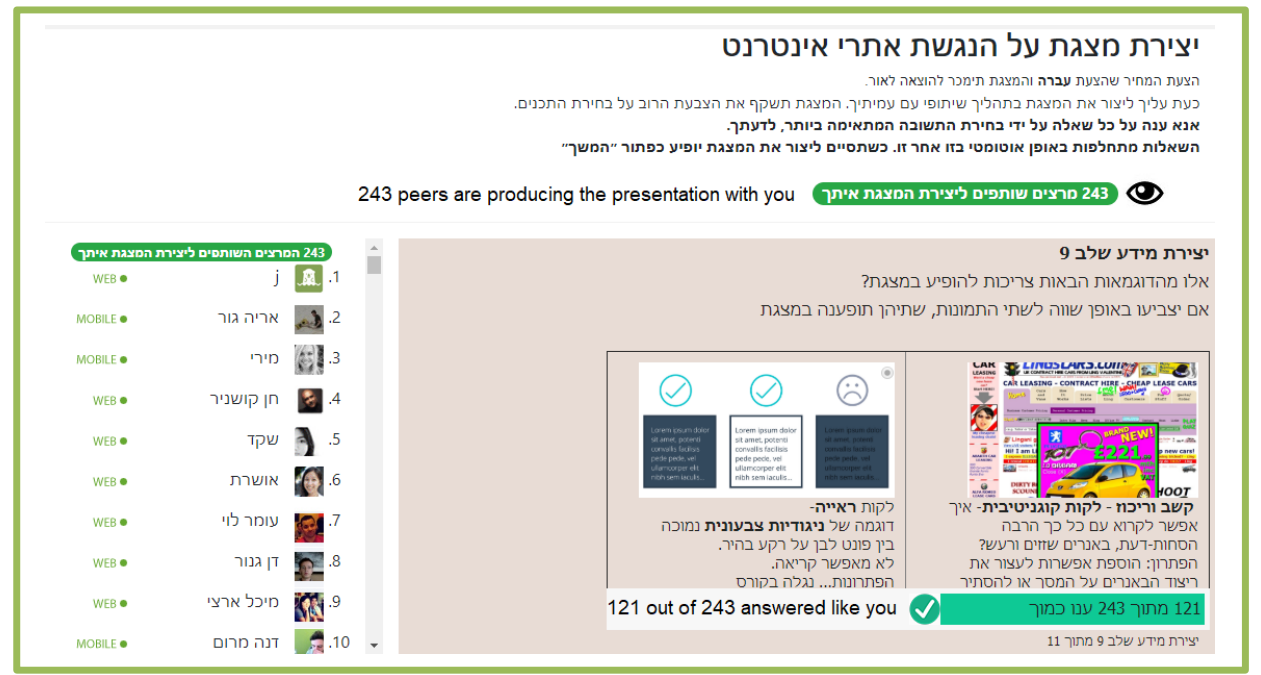

Figure 3. Sample Screenshot for Collaborative Decision Making in the Presence of 243 Producers (in Hebrew) 
The variables analyzed were:

Independent variables: (1) information experience type: consumption or production; (2) group size: $0,3,27$, or 243 peers. Participants were randomly assigned to experience type and group size.

Dependent variables: (1) Decision BEFORE experiencing information; (2) Decision AFTER experiencing information. Decision alternatives included four optional answers: (a) to pay an outsourcing company that will apply W-A knowledge; (b) to learn from web information how to apply W-A, and apply it themselves; (c) to not apply W-A knowledge; or (d) "I do not know."

To clarify, in this research, willingness to make a practical decision to apply W-A knowledge is considered a positive direction to apply W-A, whereas a negative direction reflects a lack of support for W-A. For $\mathrm{H} 2$ we assess the difference in decisions to apply W-A before and after consumption and production of information.

\section{Results}

Descriptive statistics of the variables, are displayed in Table 3.

Table 3. Descriptive Statistics of the Variables

\begin{tabular}{|c|c|c|c|c|c|c|c|c|c|c|}
\hline \multicolumn{2}{|l|}{ Experience } & & \multicolumn{4}{|c|}{ Decision BEFORE experience } & \multicolumn{4}{|c|}{ Decision AFTER experience } \\
\hline Setup & Peers & $\begin{array}{l}\text { Number of } \\
\text { participants }\end{array}$ & Outsourcing & \begin{tabular}{|l} 
Self- \\
Develop \\
ment
\end{tabular} & $\begin{array}{l}\text { No, } \\
\text { thank } \\
\text { you }\end{array}$ & $\begin{array}{l}\text { I don't } \\
\text { know }\end{array}$ & Outsourcing & $\begin{array}{l}\text { Self- } \\
\text { Develop } \\
\text { ment }\end{array}$ & $\begin{array}{l}\text { No, } \\
\text { thank } \\
\text { you }\end{array}$ & $\begin{array}{l}\text { I don't } \\
\text { know }\end{array}$ \\
\hline \multirow{4}{*}{ Consumption } & 1 & 92 & 53 & 17 & 13 & 9 & 56 & 17 & 13 & 6 \\
\hline & 3 & 78 & 27 & 30 & 7 & 14 & 27 & 38 & 3 & 10 \\
\hline & 27 & 77 & 27 & 33 & 1 & 16 & 30 & 36 & 1 & 10 \\
\hline & 243 & 59 & 16 & 26 & 6 & 11 & 28 & 29 & 0 & 2 \\
\hline \multirow{4}{*}{ Production } & 1 & 86 & 46 & 13 & 23 & 4 & 47 & 14 & 23 & 2 \\
\hline & 3 & 62 & 35 & 16 & 0 & 11 & 37 & 21 & 1 & 3 \\
\hline & 27 & 55 & 26 & 16 & 2 & 8 & 33 & 21 & 1 & 0 \\
\hline & 243 & 67 & 43 & 18 & 2 & 4 & 38 & 26 & 0 & 3 \\
\hline Total & $\mathrm{n} / \mathrm{a}$ & 576 & & & & & & & & \\
\hline No-experience $^{*}$ & $\mathrm{n} / \mathrm{a}$ & 75 & 32 & 24 & 7 & 12 & & $\mathrm{n} /$ & & \\
\hline
\end{tabular}

* - "No-experience" relates to participants who were not able to purchase or sell the information and, therefore, did not experience information. 
H1 results: A Chi-square test $\left(\chi^{2}\right)$ of independence was calculated to compare the change in decision made by participants after exposure to information in various group sizes. The test was limited to data from participants who used information (576 participants). The calculated variable change in decision was assigned with the value of ' 1 ' when participants changed their decision following the use of information, and with the value of ' 0 ' when there was no change in decision. A statistically significant main effect was found $\chi^{2}(7)=14.26, p=0.047$. Table 4 shows that the probability to change a decision when making a decision individually is 0.32 for consumers of information and 0.29 for producers. Peers in all levels of presence increase this probability in both consumption and production scenarios. Peers amplify the effect of exposure to information. Results show that among the consumers groups, the highest probability to change decision is in small groups of three peers $(\mathrm{p}=0.49)$. Among the producers groups, the highest probability to change decision is in larger groups of 27 peers $(p=0.49)$, as detailed in Table 4.

Table 4. Probability to Change Decision Following Information Experience

\begin{tabular}{|l|c|c|c|}
\hline Experience Type & Number of Peers & N & Probability to Change Decision \\
\hline \multirow{4}{*}{ Consumption } & 1 & 65 & $\mathbf{0 . 3 2}$ \\
\cline { 2 - 4 } & 3 & 41 & 0.49 \\
\cline { 2 - 4 } & 27 & 54 & 0.37 \\
\hline \multirow{4}{*}{ Production } & 243 & 37 & 0.46 \\
\cline { 2 - 4 } & 1 & 71 & $\mathbf{0 . 2 9}$ \\
\cline { 2 - 4 } & 3 & 49 & 0.39 \\
\cline { 2 - 4 } & 27 & 36 & 0.49 \\
\hline
\end{tabular}

Hypothesis H1 was accepted. Experiencing information in a collaborative platform is related to a high probability to change decision, either by consumption or by production of information.

$\mathbf{H} 2$ results: The calculated variable extent of change in decision was assigned with value 'major' for participants who (1) changed their decision from avoiding making a decision (by choosing the option 'I don't know' in the experiment interface), to a decision to act following the use of information; (2) changed their decision from a negative decision to a positive one or vice versa. The variable was assigned with the value 'minor' for participants who (1) changed their decision from supporting W-A by the use of outsourcing company to supporting W-A by self-development; (2) changed their decision from avoiding making a decision to taking a decision to not take any action or vice versa. A Chi-square test $\left(\chi^{2}\right)$ of independence was calculated comparing the extent of change in decision made by participants who used information, after their exposure to information, in various group sizes. A statistically significant main effect was found $\chi^{2}(7)=24.32$, $p=0.04$.

\section{Results for Consumers}

Based on Table 5, following are results for consumers, divided to minor and major changes: 
A minor change: The lowest probability to make a minor change in decision occurs when consuming information individually $(\mathrm{p}=0.15)$. Highest probability is when consuming information in groups of 27 peers $(p=0.20)$. The probability trend is shown in Figure 4 by a solid line.

A major change: The lowest probability to make a major change in decision occurs when consuming information in groups of 27 peers $(p=0.17)$. Highest probability is when consuming information in groups of three peers $(p=0.30)$. Probability trend is shown in Figure 5 by a solid line.

\section{Results for Producers}

Based on Table 5, following are results for producers, divided to minor and major changes.

Table 5. Probability to Make Minor or Major Changes in Decision Following Information Experience.

\begin{tabular}{|c|c|c|c|c|c|}
\hline $\begin{array}{l}\text { Experience } \\
\text { type }\end{array}$ & $\begin{array}{l}\text { Number } \\
\text { of peers }\end{array}$ & $\begin{array}{l}\mathbf{N} \\
p^{*}\end{array}$ & $\begin{array}{l}\text { Probability to NOT } \\
\text { change decision }\end{array}$ & $\begin{array}{l}\text { Probability to make } \\
\text { a MINOR change in } \\
\text { decision }\end{array}$ & $\begin{array}{l}\text { Probability to make a } \\
\text { MAJOR change in } \\
\text { decision }\end{array}$ \\
\hline \multirow{4}{*}{ Consumption } & 1 & $\begin{array}{l}\mathrm{N} \\
p\end{array}$ & $\begin{array}{c}65 \\
0.68\end{array}$ & $\begin{array}{c}14 \\
0.15\end{array}$ & $\begin{array}{c}17 \\
0.18\end{array}$ \\
\hline & 3 & $\begin{array}{l}\mathrm{N} \\
p\end{array}$ & $\begin{array}{c}41 \\
0.51\end{array}$ & $\begin{array}{c}16 \\
0.198\end{array}$ & $\begin{array}{c}24 \\
0.296\end{array}$ \\
\hline & 27 & $\begin{array}{l}\mathrm{N} \\
p\end{array}$ & $\begin{array}{c}54 \\
0.64\end{array}$ & $\begin{array}{c}17 \\
0.20\end{array}$ & $\begin{array}{c}4 \\
0.165\end{array}$ \\
\hline & 243 & $\begin{array}{l}\mathrm{N} \\
p\end{array}$ & $\begin{array}{c}37 \\
0.54\end{array}$ & $\begin{array}{c}13 \\
0.19\end{array}$ & $\begin{array}{c}18 \\
0.27\end{array}$ \\
\hline \multirow{4}{*}{ Production } & 1 & $\begin{array}{l}\mathrm{N} \\
p\end{array}$ & $\begin{array}{c}71 \\
0.71\end{array}$ & $\begin{array}{c}18 \\
0.18\end{array}$ & $\begin{array}{c}11 \\
0.11\end{array}$ \\
\hline & 3 & $\begin{array}{l}\mathrm{N} \\
p\end{array}$ & $\begin{array}{c}49 \\
0.65\end{array}$ & $\begin{array}{c}14 \\
0.18\end{array}$ & $\begin{array}{c}13 \\
0.17\end{array}$ \\
\hline & 27 & $\begin{array}{l}\mathrm{N} \\
p\end{array}$ & $\begin{array}{c}36 \\
0.51\end{array}$ & $\begin{array}{c}20 \\
0.286\end{array}$ & $\begin{array}{c}14 \\
0.20\end{array}$ \\
\hline & 243 & $\begin{array}{l}\mathrm{N} \\
p\end{array}$ & $\begin{array}{c}46 \\
0.61\end{array}$ & $\begin{array}{c}20 \\
0.267\end{array}$ & $\begin{array}{c}9 \\
0.12\end{array}$ \\
\hline
\end{tabular}

${ }^{*} p=$ probability

A minor change: The lowest probability to make a minor change in decision occurs when producing information individually $(0.18)$ and the highest probability occurs when producing information in groups of 27 peers (0.29). The probability trend is shown in Figure 4 by a dotted line. Probability to make a major change in decision increases for peer-producers up to dozens (27) of peers. Figure 4 shows probability to make a minor change in decision following consumption (solid line) and production (dotted line) of information. 


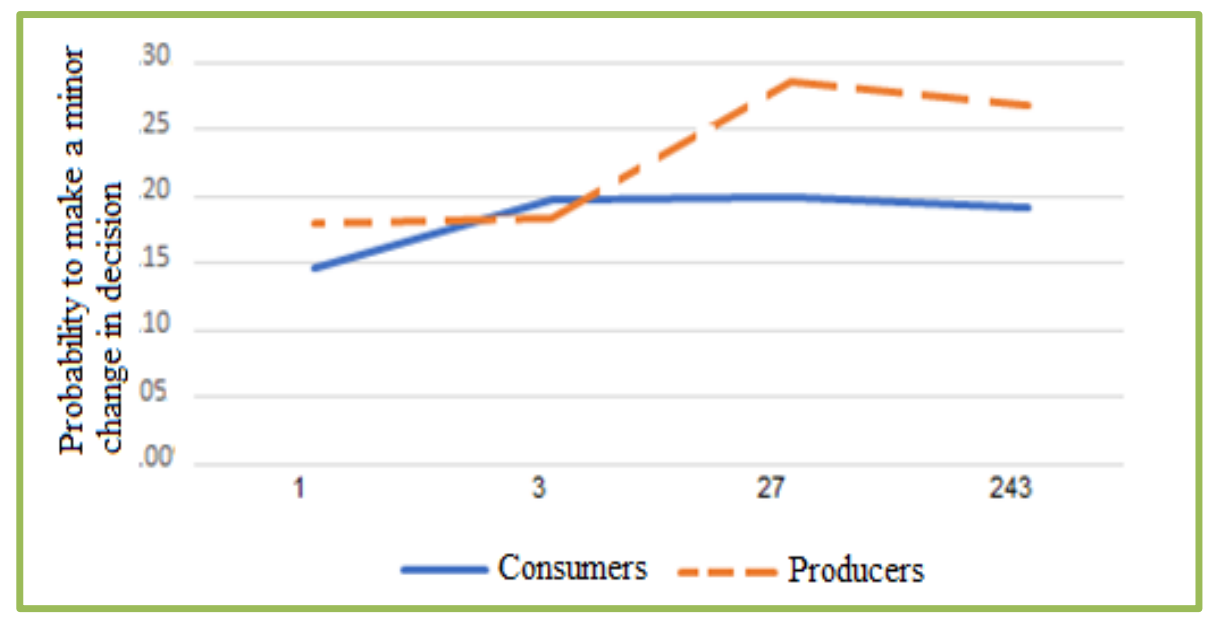

Figure 4. Trends Between Group Sizes and Probability to Make a Minor Change in Decision

A major change: Those who produced information individually ( 1 producer) were less likely to make a major change in their decision (0.11) compared to participants who produced information in groups. Probability increases when three peers join the production process $(0.17)$, and continues to increase when 27 peers join (0.20). When hundreds of peer producers join, the probability to make a major change decreases to 0.12 . The probability trend is shown in Figure 5 by a dotted line. Figure 5 shows probability to make a major change in decision following consumption (solid line) and production (dotted line) of information. Results reveal that for producers, probability to make a major change in decision increases as more peer producers join the production experience, up to 27 peers. Dozens (27) of peer producers is the upper boundary of probability to make a major change in decision for producers of information. From 27 peers, probability decreases.

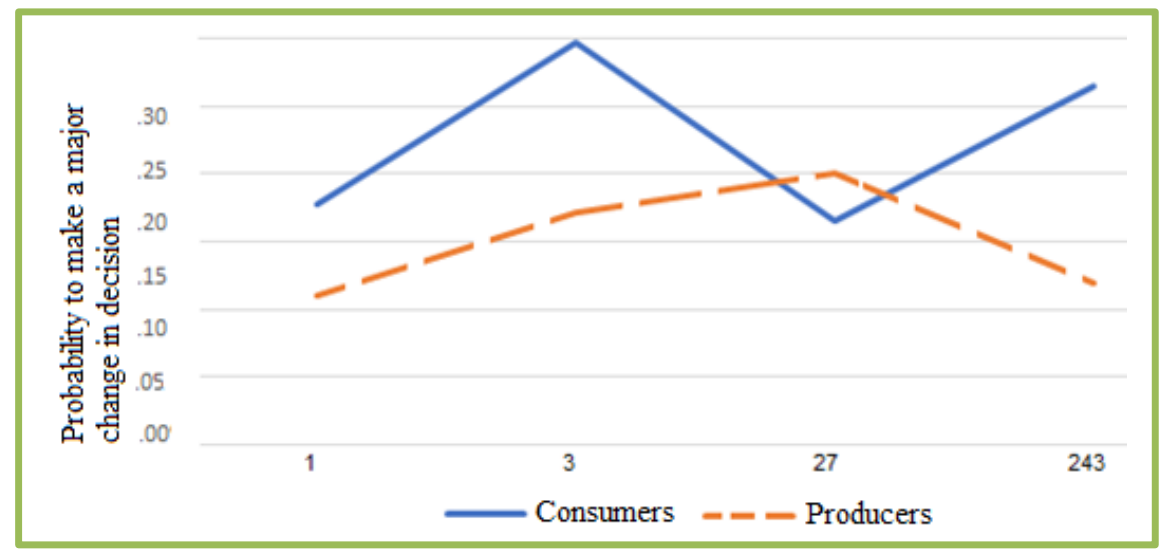

Figure 5. Trends Between Group Sizes and Probability to Make a Major Change in Decision

Hypothesis $\mathrm{H} 2$ was accepted. A statistically significant main effect was found, meaning that the extent of change in decision is related to the number of peers collaborating.

H3 results: To fine tune, we created a new calculated variable: final decision. A value of '1' was assigned to participants whose final decision was to apply W-A knowledge (Options 1 \& 2). For participants who did not purchase or sell their information and thus did not experience information, 
their initial intent to apply W-A knowledge was taken as their final decision. For participants who experienced information, it was their final intent to apply W-A following the use of information. A final decision to not take any practical action was assigned with the value of ' 0 '. Final decision does not take under consideration any previous decisions and thus we report only the final decision taken by participants. A Phi correlation test $(\Phi)$ was calculated to analyze the relationship between the use of information (used information $=1$, no use of information $=0$ ) and a final decision made by participants (practical final decision=1, non-practical decision=0). The results indicate that people who use information are significantly associated with making practical decisions $(\mathrm{p}=0.865)$ than people who do not use information $(\mathrm{p}=0.747) \Phi=.106, p=0.007$. Results are displayed in Table 6.

Table 6. Probability to Make a Final Practical Decision With or Without Using Information

\begin{tabular}{|l|l|c|c|}
\hline Information Use & N & $\begin{array}{l}\text { Probability to NOT MAKE } \\
\text { a final practical decision }\end{array}$ & $\begin{array}{l}\text { Probability to MAKE a } \\
\text { final practical decision }\end{array}$ \\
\hline WITHOUT information experience & $\mathrm{N}$ & 19 & 56 \\
\hline WITH information experience & $\mathrm{N}$ & 0.25 & 0.747 \\
& $P$ & 78 & 498 \\
\end{tabular}

Hypothesis H3 was accepted. The use of information increases probability to take a practical decision.

H4 results: A Chi-square test $\left(\chi^{2}\right)$ of independence was calculated comparing the final decision made by participants after various experiences of information. The calculated variable final decision was assigned with a value of 1 for participants whose final decision was to support $\mathrm{W}-\mathrm{A}$ following the use of information. A significant main effect was found $\chi^{2}(7)=41.20, p<0.0001$. Results suggest that consumers and producers making decisions on their own were less likely to make practical decisions than in the peer groups. Moreover, results suggest that consumers in 243 peers group size and producers in 27 and three peers group size have the highest probability to make practical decisions, as displayed in Table 7 in descending probability order, where producers are highlighted in bold.

Table 7. Probability to Make a Final practical Decision According to Information Experience

\begin{tabular}{|l|l|c|}
\hline Experience Type and Extent & $\mathbf{N}$ & Probability to Make a Practical Decision \\
\hline 27 peer-producers & 69 & 0.986 \\
\hline 243 peer-consumers & 65 & 0.956 \\
\hline 3 peer- producers & 72 & 0.947 \\
\hline 243 peer- producers & 71 & 0.947 \\
\hline 27 peer-consumers & 72 & 0.847 \\
\hline 3 peer-consumers & 68 & 0.84 \\
\hline 1 peer-consumer & 77 & 0.80 \\
\hline 1 peer-producer & 74 & 0.74 \\
\hline
\end{tabular}


Hypothesis H4 was accepted. Experiencing information in groups is associated with higher probability to take a practical decision, compared to individual experience, especially in the case of production experience, where even small groups have a significant influence.

Interaction effect between two independent variables: A two-way Analysis of Variance (ANOVA) was conducted on the influence of two independent variables (group size, experience type) on probability to make a practical decision. Meaning that whether probability increases or decreases in relation to group sizes depends on the type of experience condition. Group sizes included four levels $(1,3,27$, or 243 peers) and type of experience consisted of two levels (consumption or production). The main effect for group size yielded a significant difference between using information individually $(\mathrm{M}=0.75, \mathrm{SD}=0.433, \mathrm{~N}=178)$, using in groups of three peers $(\mathrm{M}=0.88, \mathrm{SD}=0.328, \mathrm{~N}=140)$, using in groups of 27 peers $(\mathrm{M}=0.91, \mathrm{SD}=0.289, \mathrm{~N}=132)$ and using in groups of 243 peers $(\mathrm{M}=0.96, \mathrm{SD}=0.196, \mathrm{~N}=126), \mathrm{F}(3,568)=11.71, p<0.0001$. The main effect for experience type indicated that the effect for experience type was not significant, consumers $(\mathrm{M}=0.85, \mathrm{SD}=0.355, \mathrm{~N}=306)$ and producers $(\mathrm{M}=0.88, \mathrm{SD}=0.328, \mathrm{~N}=270), \mathrm{F}(1$, $568)=1.38, p=0.246$. The interaction effect was significant, $\mathrm{F}(3,568)=3.31, p=0.020$. The interaction between experience and group size affects the probability to make a practical decision is shown in Figure 6.

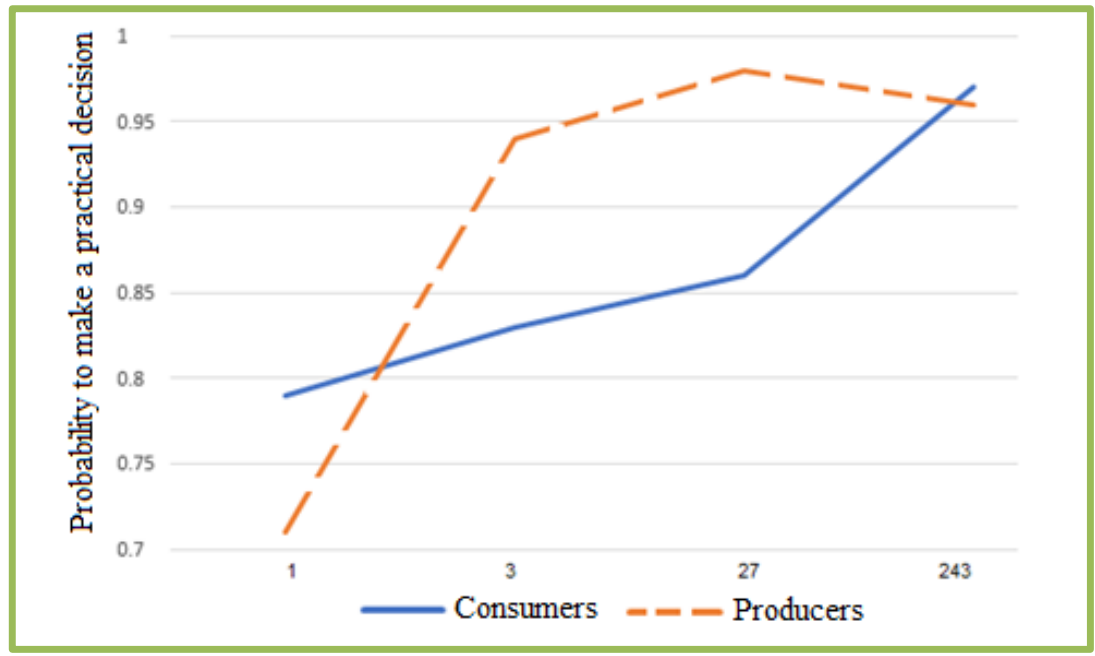

Figure 6. Interaction Between Group Size and Probability to Make a Practical Decision

\section{Discussion}

The main finding of the present research is that to make knowledge actionable, it is advisable to experience information in a social environment. In our case, the presence of peers in the process of consuming or producing information led to higher probability to apply W-A knowledge. By comparing participants who used information with participants who did not use information; and by comparing consumption with production information experiences, in four peer group sizes, the varying effects of information experience emerged. Results are discussed in three steps: changing a decision; the extent of changing a decision, including reference to valence; making a final practical decision following the use of information. 


\section{Changing a Decision:}

The quest for knowledge through information consumption in the information age is growing. People consume information selectively, based on subjective value and expected outcomes (Ambuehl \& Li, 2014; Hall et al., 2018; Levy et al., 2010). Yet, people choose information that assists them in justifying their initial beliefs. The tendency to seek and use information in a way that confirms one's existing beliefs is known as confirmation bias (Nickerson, 1998; Wason, 1960). People have a tendency to overestimate their judgment and thus fail to consider other beliefs (Mynatt et al., 1977). As a result, people prefer to maintain their initial position (Lord et al., 1979). It is therefore reasonable to assume that people will not change their decisions following information experiences, even if it is embedded in knowledge management definitions. Nevertheless, this research found that experiencing information in the presence of peers does indeed affect the probability of changing a decision. Results suggest that both in the consumer and producer groups, those who experienced information individually were less likely to change their decisions compared to participants who experienced information in collaborative groups. These findings are consistent with the social proof theory (Cialdini, 1987), referring to the tendency of people to copy other people's behavior. Results show that when participants consume or produce information individually, tendency to refuse to apply W-A (by selecting "No, thank you") is high. The highest number of participants who chose not to apply W-A knowledge before and after the experience, is in the single consumers and single producers' experiments.

Comparing consumers and producers in terms of probabilities to change decisions reveals that producers are less eager to change their decision compared to consumers, in contrast to our early expectations. Following the production experience process, producers maintain their original decisions and are not fervent to change them. The influence of the production experience repeats itself in the presence of peers: in the groups of three peer consumers, the probability to change decision was higher than in the group of three peer producers. In the groups of 243 peer consumers, the probability to change decision was higher than in the group of 243 peer producers. Interestingly, the only group size where probability to change a decision was higher for producers than for consumers was in the dozens (27) peers. For dozens of peer producers, probability to change decision was almost 0.49 , where probability in the group of dozens of peer consumers, probability to change a decision was only 0.37 .

\section{Extent of Changing a Decision:}

A change in a decision does not necessarily indicate the extent of the change: the change can be minor or major. Therefore, the second hypothesis compared extent of change in decision after experiencing information in varying peer group sizes. A major change refers to changing decisions from avoiding making a decision to a decision to act, or to cases when participants changed their decision from a negative to a positive one, or vice versa. Starting with consumption experience, the lowest probability to make a major change in decision was by individual consumers. When three peers join, probability increases, with further increase in the presence of 27 peers, probability increases again. This trend is shown in Figure 5 (solid line). In the presence of hundreds of peers, probability to make a major change in decision decreases. Continuing to production experience, this study reveals that producers who experience information individually are less likely to make a major change in a decision compared to producers who experience information as part of a 
collaborative activity. Probability to make a major change increases when more peers join the production process (up to 27 peer producers). When hundreds of producers join, the probability of making a major change decreases. This trend is shown in Figure 5 (dotted line).

\section{Making a Final Practical Decision:}

The last two hypotheses examined the influence of information experience on the tendency to make practical decisions. The third hypothesis compares final practical decisions made following the use of information, to practical decisions make without use of information. We find that following the use of information, practical decisions increases by $11.8 \%$. Experiencing information increases the intent to apply W-A. A practical decision occurs when a participant's final decision is to take an action to apply W-A knowledge, as opposed to final decisions by participants not to apply W-A. Focusing on the experience itself, results suggest that consumers and producers in the individual level were less likely to make practical decisions compared to consumers and producers who experienced collaborative information exposure. Experiencing information in groups is associated with a higher probability of deciding to act, especially in the cases of production experience, than when experiencing information individually. In the case of consumption of information, large groups are needed to have a similar effect. In other words, in order for consumption use of information to influence the direction of the change in decision, information must be consumed in mass consumption peer groups. Overall, active involvement in information production coupled with a social environment is conducive to the adoption of $\mathrm{W}-\mathrm{A}$ and constitutes an efficient way to promote knowledge exposure in an inclusive manner.

\section{Limitations}

The research method employed in this study was an experiment, which was the main limitation. Although efforts were made to reduce the effect of interruptions, there is no certainty that other factors outside the experiment itself affected the results. Nevertheless, it is arguable that these outside factors are in any event part of the overall experience that affects decision-making. In order to be able to apply the conclusions outside the context of this study, we used a real-world online interface and a contemporary challenge in the field of W-A, in which both consumers and producers of information on the web are involved due to social influences and requirements by regulations. Information disclosed to producers and consumers was identical.

\section{Future Work}

The current study focuses on the influences of information experience on making decisions, as part of information-based assignment concerning W-A. Further research should examine additional types of information experience, prosumers who switch roles between being producers and consumers of information, and varying information products and contexts. Since the subject under discussion relates to practical decision making, it is recommended that future study will examine the impact information use on decision-making among managers and employees in organizations, lecturers and students, teachers and students, and so on. Moreover, broader scenarios other than $\mathrm{W}-\mathrm{A}$ are suggested to be investigated. For example, decisions regarding health care or strategic decisions. Further to the findings obtained in the experiments- A positive relationship was found between the number of peers producing information and the probability to make a major change in decision, in line with the diminishing value of information (Rusho \& Raban, 2018, 2019). Self- 
production, which leads to the highest value perception, exemplifies the low probability to make a major change in decision following the production process. It follows that the higher the value of information as a result of labor, the lower a person's readiness to make a major change in his or her decisions. Investing in information production leads to stronger entrenchment in initial decisions. Future research should further investigate the links between information production, value perception and probability to make major change in decisions. Finally, future research can apply the procedure in the current study and conduct experiments for additional group sizes.

\section{Conclusion}

With the aim of finding the links between information usage and decision to apply W-A knowledge in practice, this research compared two types of information usage: consuming and producing a presentation about W-A. Each type of information usage was applied to four group sizes- from using as individuals to groups of hundreds of peers joining in the information experience activity. The main findings in this research are divided to three tiers: the first tier refers to the impact of using information to changing decisions. This study reveals that about half of the participants are not eager to change their decisions and prefer to be entrenched in their original views. However, following a short 20 minutes experiment, experiencing information indeed influences decisionmaking of the other half of the participants. Furthermore, probability to change decision is greater when information is experienced in groups. The second tier in this study refers to the extent of the change, showing the clear difference between information consumers and information producers. Results reveal that the extent of change in decision is related to number of producers collaborating. The third tier in this research compared users of information with participants who did not use information. In addition, the third tier investigated the link between information usage and probability to make an actionable decision. Results revealed that the use of information increases probability to take a practical decision. Moreover, mass consumption and producing information in a collaborative environment increase the intent to make a practical decision to apply W-A.

The web requires extensive support for W-A. There is social and economic awareness of the importance of accessibility, and there are technical tools and professionals who know how to support W-A. Moreover, free information regarding how to support accessibility exists on the web. Still, the web is far from being fully supported for everyone using it. For that reason, the current study's goal was to find the link between information usage and decision-making. Thus, contributions are both academic and practical. In order to promote greater involvement in applying $\mathrm{W}$-A knowledge, this study recommends teamwork to jointly consume and produce information about W-A in organizations. Users who adopt collaborative practices tend to adhere to collaborative environments. In addition, they are more open to producing collaborative products.

\section{References}

Alahmadi, T., \& Drew, S. (2017). Accessibility evaluation of top-ranking university websites in world, Oceania, and Arab categories for home, admission, and course description webpages. Journal of Open, Flexible and Distance Learning, 21(1), 7-24. https://search.informit. com.au/documentSummary;dn=957118278379895;res=IELHSS 
Alstyne, M. W. Van. (1999). A proposal for valuing information and instrumental goods. Proceedings of the 20th International Conference on Information Systems, 20, 328-345.

Ambuehl, S., \& Li, S. (2014). Belief updating and the demand for information. In SSRN. https://doi.org/10.2139/ssrn.2461904

Anderson, A., Huttenlocher, D., Kleinberg, J., \& Leskovec, J. (2012). Discovering value from community activity on focused question answering sites. Proceedings of the 18th ACM International Conference on Knowledge Discovery and Data Mining, 850-858. https://doi.org/10.1145/2339530.2339665

Berners-Lee, T. (2013). The power of the Web is in its universality. Access by everyone regardless of disability is an essential aspect. http://blogs.ubc.ca/pkp2009/files/2009/07/ felczak_pkp_2009.pdf

Borras-Gene, O., Martiñez-nunez, M., \& Fidalgo-Blanco, Á. (2016). New challenges for the motivation and learning in engineering education using gamification in MOOC. International Journal of Engineering Education, 32(1), 501-512.

Brown, J., \& Hollier, S. (2015). The challenges of Web accessibility: The technical and social aspects of a truly universal Web. First Monday, 20(9), 1-16. https://doi.org/10.5210/fm.v20i9.6165

Chen, D., Fisch, A., Weston, J., \& Bordes, A. (2017). Reading Wikipedia to answer open-domain questions. http://arxiv.org/abs/1704.00051

Cialdini, R. (1987). Influence. http://videoplus.vo.llnwd.net/o23/digitalsuccess/SUCCESS\%20 Book\%20Summaries/2011\%20June\%20SBS/Influence\%20Summary.pdf

Flórez-Aristizábal, L., Cano, S., Collazos, C. A., Solano, A. F., \& Brewster, S. (2019). Designability: Framework for the design of accessible interactive tools to support teaching to children with disabilities. Proceedings of the Conference on Human Factors in Computing Systems. https://doi.org/10.1145/3290605.3300240

Freire, Andre P., Russo, C. M., \& Fortes, R. P. M. (2008). A survey on the accessibility awareness of people involved in web development projects in Brazil. Proceedings of the 2008 International Cross-Disciplinary Workshop on Web Accessibility, 87-96. https://doi.org/10.1145/1368044.1368064

Freire, Andre Pimenta, Goularte, R., \& de Mattos Fortes, R. P. (2007). Techniques for developing more accessible web applications. Proceedings of the 25th Annual ACM International Conference on Design of Communication, 162-169. https://doi.org/10.1145/1297144.1297177

Girard, J., \& Girard, J. (2015). Defining knowledge management: Toward an applied compendium. Online Journal of Applied Knowledge Management, 3(1), 1-20.

Hall, S., Champoux, R., Garver, S., Harriott, C., \& Chauncey, K. (2018). Designing the user experience of a co-adaptive data analytics interface in response to user trait. Wepir.Adaptcentre.Ie. https://wepir.adaptcentre.ie/papers/WEPIR_2018_paper_4.pdf 
Heidrich, B., Kása, R., Shu, W., \& Chandler, N. (2015). Worlds apart but not alone: How wiki technologies influence productivity and decision-making in student groups. Decision Sciences Journal of Innovative Education, 13(2), 221-246.

https://doi.org/10.1111/dsji.12062

Henry, S. L., Abou-Zahra, S., \& Brewer, J. (2014). The role of accessibility in a universal web. Proceedings of the 11th Web for All Conference, 1-4. https://doi.org/10.1145/2596695.2596719

Henry, S. L., \& Thorp, J. (2012). Web content accessibility and mobile web: Making a website accessible both for people with disabilities and for mobile devices. Web Accessibility Initiative, W3C. https://www.w3.org/WAI/standards-guidelines/wcag-mobile-overlap/

Hong, S. G., Trimi, S., Kim, D. W., \& Hyun, J. H. (2015). A Delphi study of factors hindering web accessibility for persons with disabilities. Journal of Computer Information Systems, 55(4), 28-34. https://doi.org/10.1080/08874417.2015.11645784

Kavasidis, I., Palazzo, S., Salvo, R. Di, Giordano, D., \& Spampinato, C. (2014). An innovative web-based collaborative platform for video annotation. Multimedia Tools and Applications, 70(1), 413-432. https://doi.org/10.1007/s11042-013-1419-7

Kiesler, S., \& Sproull, L. (1992). Group decision making and communication technology. Organizational Behavior and Human Decision Processes, 52(1), 96-123. https://doi.org/10.1016/0749-5978(92)90047-B

Levy, I., Snell, J., Nelson, A. J., Rustichini, A., \& Glimcher, P. W. (2010). Neural representation of subjective value under risk and ambiguity. Journal of Neurophysiology, 103(2), 10361047. https://doi.org/10.1152/jn.00853.2009

Li, J., Kim, S., Miele, J. A., Agrawala, M., \& Follmer, S. (2019). Editing spatial layouts through tactile templates for people with visual impairments. Proceedings of the Conference on Human Factors in Computing Systems, 1-11. https://doi.org/10.1145/3290605.3300436

Lorca, P., Andrés, J. De, \& Martínez, A. B. (2018). The relationship between web content and web accessibility at universities. Social Science Computer Review, 36(3), 311-330. https://doi.org/10.1177/0894439317710435

Lord, C. G., Ross, L., \& Lepper, M. R. (1979). Biased assimilation and attitude polarization: The effects of prior theories on subsequently considered evidence. Journal of Personality and Social Psychology, 37(11), 2098-2109. https://doi.org/10.1037/0022-3514.37.11.2098

Mynatt, C. R., Doherty, M. E., \& Tweney, R. D. (1977). Confirmation bias in a simulated research environment: An experimental study of scientific inference. Quarterly Journal of Experimental Psychology, 29(1), 85-95. https://doi.org/10.1080/00335557743000053

Nelson, P. (1970). Information and consumer behavior. Journal of Political Economy, 78(2), 311-329. https://doi.org/10.1086/259630

Nickerson, R. S. (1998). Confirmation bias: A ubiquitous phenomenon in many guises. Review of General Psychology, 2(2), 175-220. 
Norton, M. I., Mochon, D., \& Ariely, D. (2012). The IKEA effect: When labor leads to love. Journal of Consumer Psychology, 22(3), 453-460. https://doi.org/10.1016/j.jcps.2011.08.002

Owyang, J., Tran, C., \& Silva, C. (2013). A market definition report includes input from 69 ecosystem contributors. http://www.collaboriamo.org/media/2014/04/collabecon-draft16130531132802-phpapp02-2.pdf

Ramakrishnan, I. V., Ashok, V., \& Billah, S. M. (2017). Non-visual web browsing: Beyond web accessibility. Lecture Notes in Computer Science (Including Subseries Lecture Notes in Artificial Intelligence and Lecture Notes in Bioinformatics), 10278 LNCS, 322-334. https://doi.org/10.1007/978-3-319-58703-5_24

Rau, P. L. P., Zhou, L., Sun, N., \& Zhong, R. (2016). Evaluation of web accessibility in China: changes from 2009 to 2013. Universal Access in the Information Society, 15(2), 297-303. https://doi.org/10.1007/s10209-014-0385-9

Rusho, Y., \& Raban, D. R. (2018). The effects of information production process on experience and evaluationes. Proceedings of the 19th Annual Conference of the Association of Internet Researchers. Papers R. https://spir.aoir.org/ojs/index.php/spir/article/view/10504

Rusho, Y., \& Raban, D. R. (2019). Hands on: Information experiences as sources of value. Journal of the Association for Information Science and Technology, asi.24288. https://doi.org/10.1002/asi.24288

Sillito Walker, S. D., \& Bonner, B. L. (2018). The effects of differing knowledge transfer strategies on group decision making and performance. Journal of Behavioral Decision Making, 31(1), 115-126. https://doi.org/10.1002/bdm.2053

Sołtysik-Piorunkiewicz, A. (2015). The evaluation method of Web 2.0/3.0 usability in e-health knowledge management system. Online Journal of Applied Knowledge Management, 3(2), $168-180$.

The W3C Markup Validation Service. (n.d.). http://validator.w3.org/

Wason, P. C. (1960). On the failure to eliminate hypotheses in a conceptual task. Quarterly Journal of Experimental Psychology, 12(3), 129-140. https://doi.org/10.1080/17470216008416717

WAVE Web Accessibility. (2015). WAVE Web Accessibility Tool. Webaim.Org. https://wave.webaim.org/

Wilson, K., Bhakoo, V., \& Samson, D. (2017). Crowdsourcing: How is value created? Academy of Management Proceedings, 2017(1), 10606. https://doi.org/10.5465/ambpp.2017. 10606abstract

Yesilada, Y., Brajnik, G., Vigo, M., \& Harper, S. (2015). Exploring perceptions of web accessibility: A survey approach. Behaviour \& Information Technology, 34(2), 119-134. https://doi.org/10.1080/0144929X.2013.848238 


\section{Authors Biographies}

Yonit Rusho, Ph.D. Head of the Software Engineering Department at Shenkar College. Holds a PhD in Information Science from the University of Haifa and a member of LINKS, the Israeli Center of Research Excellence on learning in a Networked Society, of the Internet Research Lab and of the Data Science Center, Israel. She holds a Master of Business Administration and a Software Engineer Diploma. Her areas of expertise include information science, Social Network Analysis (SNA) and Internet and Cloud Engineering. Her work has been published in refereed journals including JASIST, Open Information Science and in international conferences.

Daphne R. Raban, Ph.D. is an Associate Professor, founding Head of the Department of Information \& Knowledge Management at the University of Haifa and a member of LINKS, the Israeli Center of Research Excellence on Learning in a Networked Society, of the Internet Research Lab and of the Data Science Center.

Her areas of expertise include the information society and the information economy as well as bibliometry; specifically, she studies information markets and business

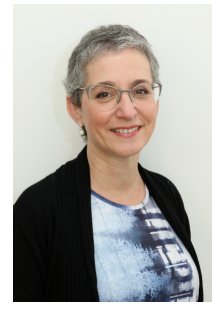
models, knowledge sharing, information diffusion, social media, serious games and novel approaches to science measurement. Her work has been published in refereed journals including JCMC, JASIST, EJIS, ICS, CHB, JIS, PLOS One, Internet Research, Scientometrics, Simulation \& Gaming and more. 